\title{
Short-Term Facilitation Modulates Size and Timing of the Synaptic Response at the Inner Hair Cell Ribbon Synapse
}

\author{
Juan D. Goutman and Elisabeth Glowatzki \\ Center for Hearing and Balance and Center for Sensory Biology, The Johns Hopkins School of Medicine, Departments of Otolaryngology-Head and Neck \\ Surgery and Neuroscience, Baltimore, Maryland 21205
}

Inner hair cells (IHCs) in the mammalian cochlea are able to continuously release neurotransmitter in the presence of constant stimuli. Nonetheless, strong synaptic depression is observed over the first few milliseconds of stimulation. This process most likely underlies adaptation in the auditory nerve. In the present study we demonstrate that under certain conditions of stimulation, facilitation can occur at the IHC ribbon synapse. Using simultaneous whole-cell, voltage-clamp recordings from IHCs and afferent fiber endings in excised postnatal rat cochleae, we stimulated IHCs with $2 \mathrm{~ms}$ long test depolarizations from a holding potential of $-89 \mathrm{mV}$. Synaptic currents in afferent fibers occurred with high failure rates of $\sim 50 \%$. However, when a pre-depolarization to values of -55 to $-49 \mathrm{mV}$ was implemented before the test pulse, success rates of the synaptic response increased to $100 \%$, the strength of the synaptic response increased $\sim 2.8$-fold, and synaptic latency was reduced by $\sim 50 \%$. When calcium influx was minimized during pre-depolarization, none of these effects were found, suggesting that calcium influx during pre-depolarizations is required for synaptic conditioning. Similarly, in response to paired-pulse protocols, short term facilitation occurred. The response to the second stimulus increased up to $\sim 5$-fold, and its latency was reduced by up to $35 \%$ compared to the response to the first stimulus. We propose that at the IHC resting membrane potential, the ribbon synapse operates in a constantly facilitated mode caused by $\mathrm{Ca}^{2+}$ influx, optimizing the size and timing of the postsynaptic response in auditory nerve fibers.

\section{Introduction}

Coding of sound information in the mammalian cochlea requires high temporal precision and sustained transmission over long periods of time. This imposes stringent conditions on the performance of the ribbon synapse between an inner hair cell (IHC) and the afferent neurons, the first synapse in the auditory pathway (Fuchs, 2005). A single afferent neuron, typically fed by a single synaptic ribbon, is able to encode submillisecond signals, indicating how accurately neurotransmission occurs at this synapse (Ruggero, 1992). Additionally, IHCs release vast amounts of vesicles over long periods of time, drawing from a large reserve pool of vesicles (Nouvian et al., 2006). In response to sound signals with constant intensity, auditory nerve fiber activity adapts (Galambos and Davis, 1943; Kiang et al., 1965; Furukawa and Matsuura, 1978), most likely caused by exhaustion of presynaptic vesicles ready for release (Moser and Beutner, 2000; Spassova et al., 2004; Johnson et al., 2005; Schnee et al., 2005;

Received Feb. 3, 2011; revised April 4, 2011; accepted April 11, 2011.

Author contributions: J.D.G. and E.G. designed research; J.D.G. performed research; J.D.G. and E.G. analyzed data; J.D.G. and E.G. wrote the paper.

This work was supported by National Institute on Deafness and Other Communication Disorders Grants DC006476 to E.G. and DC005211 to the Center for Hearing and Balance, Johns Hopkins University, Human Frontiers Science Program Research Grant RGY19/2004 to E.G., and a National Organization for Hearing Research Foundation 2010 Research Award and PICT 20080104 to J.D.G.

The authors declare no conflict of interest.

Correspondence should be addressed to Juan D. Goutman at his present address: Instituto de Investigaciones en Ingeniería Genética y Biología Molecular (UBA-CONICET), Vuelta de Obligado 2490, C1428ADN Ciudad de Buenos Aires, Argentina. E-mail: goutman@dna.uba.ar.

DOI:10.1523/JNEUROSCI.0604-11.2011

Copyright $\odot 2011$ the authors $\quad 0270-6474 / 11 / 317974-08 \$ 15.00 / 0$
Goutman and Glowatzki, 2007; Li et al., 2009). In general, synapses are classified as depressing or facilitating (or both), depending on their dynamics in response to repetitive stimulation (Zucker and Regehr, 2002). In this respect, the IHC ribbon synapse can be considered a depressing synapse; however, other forms of short term plasticity have not been investigated yet.

In contrast to CNS neurons, mature IHCs do not fire action potentials but instead produce graded receptor potentials in response to sound (Russell and Sellick, 1978). Also, the IHC resting membrane potential appears to be more depolarized than in nerve cells (at $-60 \mathrm{mV}$ or more positive values) (Russell and Sellick, 1978; Kros et al., 1998). Thus, at rest (in the absence of acoustic inputs), a fraction of the L-type voltage-gated $\mathrm{Ca}^{2+}$ channels located at IHC afferent synapses is activated (Brandt et al., 2005; Johnson et al., 2005; Grant and Fuchs, 2008), resulting in transmitter release and "spontaneous firing" in auditory nerve fibers (Robertson and Paki, 2002). It is likely that these special conditions affect the behavior of the IHC synapse. However, IHC synaptic transmission has mostly been investigated by step depolarizations of the IHC membrane potential from artificially negative holding potentials of -90 to $-70 \mathrm{mV}$ (Parsons et al., 1994; Moser and Beutner, 2000; Spassova et al., 2001; Johnson et al., 2005; Schnee et al., 2005; Keen and Hudspeth, 2006; Goutman and Glowatzki, 2007; Li et al., 2009).

Here, we investigate how the level of the IHC membrane potential preceding a test depolarization affects transmitter release. We show that pre-depolarizations to membrane potentials of -55 to $-49 \mathrm{mV}$ (rather than holding at $-89 \mathrm{mV}$ ) strengthen the synaptic response to short test depolarizations. This process re- 
quires the influx of calcium in a time-dependent manner. Additionally, pre-depolarization shortens the latency of the synaptic response. In paired-pulse protocols with brief stimuli, facilitation is also unmasked.

We suggest that $\mathrm{Ca}^{2+}$ influx into the IHC at rest shifts the release mechanism at the ribbon synapse into a constantly facilitated mode, resulting in improved synaptic strength and more precise timing.

\section{Materials and Methods}

Recordings of IHCs and afferent postsynaptic boutons. Excised apical turns of 9- to 11-d-old rat cochleae (either sex; Sprague Dawley, Charles River) were placed into a chamber under an upright microscope (Axioskop2 FS plus, Zeiss) and superfused with saline at $2-3 \mathrm{ml} / \mathrm{min}$. IHCs and contacting postsynaptic terminals were visualized on a monitor via a $40 \times$ waterimmersion objective, $4 \times$ magnification, difference interference contrast optics using a green filter, and a Newvicon camera (Dage-MTI). For simultaneous whole-cell, patch-clamp recordings, the postsynaptic recording was established first and the IHC recording second.

Pipette solution for isolating $\mathrm{IHC} \mathrm{Ca}^{2+}$-currents (in $\mathrm{mM}$ ): 135 $\mathrm{CsMeSO}_{3}, 13$ tetraethylammonium chloride (TEA-Cl), 5 HEPES, 3.5 $\mathrm{MgCl}_{2}, 2.5 \mathrm{Na}_{2} \mathrm{ATP}, 1$ EGTA, pH $7.2(\mathrm{CsOH})$; liquid junction potential (LJP), $9 \mathrm{mV}$. Postsynaptic pipette solution (in $\mathrm{mm}$ ): $135 \mathrm{KCl}, 3.5 \mathrm{MgCl}_{2}$, $0.1 \mathrm{CaCl}_{2}$, 5 EGTA, 5 HEPES, $2.5 \mathrm{Na}_{2} \mathrm{ATP}$, pH $7.2(\mathrm{KOH})$; LJP, $4 \mathrm{mV}$. Extracellular solution: $5.8 \mathrm{KCl}, 114 \mathrm{NaCl}, 0.9 \mathrm{MgCl}_{2}, 1.3 \mathrm{CaCl}_{2}, 0.7$ $\mathrm{NaH}_{2} \mathrm{PO}_{4}, 5.6$ D-glucose, 10 HEPES, 30 TEA-Cl; pH $7.4(\mathrm{NaOH})$ and 1-5 $\mu \mathrm{M}$ tetrodotoxin (Alomone Labs). All other chemicals were purchased from Sigma.

Recording pipettes were fabricated from $1 \mathrm{~mm}$ borosilicate glass (WPI), Sylgard coated and fire polished with tip resistances of 9-12 (postsynaptic) and 6-8 (IHC) M $\Omega$. Series resistance errors, 10-20 M $\Omega$ for IHC recordings, were compensated up to $70 \%$. Holding potentials were corrected for LJPs. Experiments were done at $22-24^{\circ} \mathrm{C}$. Recordings were performed with a 200A and a 200B Axopatch amplifier and Digidata 1322A board (Molecular Devices), filtered at $10 \mathrm{kHz}$, and digitized at 50 $\mathrm{kHz}$. Data acquisition started 5-10 min after the IHC whole-cell recording. During this time, a run-up of $\mathrm{Ca}^{2+}$-currents was typically observed. After $\sim 40$ min of recording, run-down of synaptic activity was observed and therefore only data recorded within this time window were analyzed.

Data analysis. Data were analyzed off-line using pClamp Version 9.2 (Molecular Devices), Minianalysis (Synaptosoft), and Origin 7.5 (OriginLab). For leak subtraction of IHC currents, IHC membrane resistance was calculated from voltage steps between -89 and $-69 \mathrm{mV} . \mathrm{Ca}^{2+}$ charge was calculated by the integral of the $\mathrm{Ca}^{2+}$ current from its onset time up to $2 \mathrm{~ms}$ after the end of the depolarizing pulse to include the tail current in the analysis. The onset time was, in turn, computed as the time point where the $\mathrm{Ca}^{2+}$ current trace crossed baseline (in the negative direction) after test depolarization started. Activation time constant $\left(\tau_{\text {act }}\right)$ was obtained by fitting the activation time course of the $\mathrm{Ca}^{2+}$ current from the onset time to the peak. Postsynaptic response amplitude was calculated as the sum of all EPSCs triggered by a given test pulse. Synaptic delay was computed from the onset of a test pulse until the onset of the first EPSC.

If not specified in Results, for statistical comparison two-tailed Student's $t$ test or one-way ANOVA (OriginLab) was used. Mean values are presented \pm standard error (SE.).

\section{Results}

The IHC membrane potential before stimulation sets release probability and synaptic delay during stimulation

Here, we study how the setting of the IHC membrane potential preceding a test depolarization affects transmitter release at the IHC afferent synapse. For this purpose, we performed paired whole-cell, patch-clamp recordings from IHCs and postsynaptic afferent fiber boutons directly where they contact the IHC in excised postnatal rat cochlear turns (days 9 to 11), as described earlier (Goutman and Glowatzki, 2007). IHCs were depolarized by voltage step protocols, and IHC $\mathrm{Ca}^{2+}$ currents and postsyn-
A

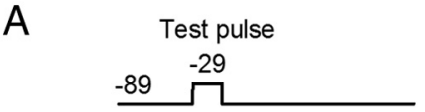

B
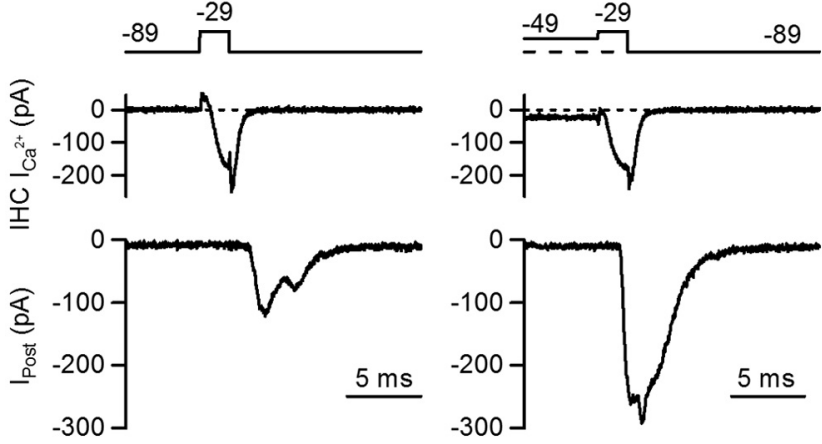

Figure 1. The IHC membrane potential before stimulation sets release probability during stimulation. Simultaneous whole-cell, voltage-clamp recordings from IHC and contacting postsynaptic bouton are shown. Voltage command and pharmacologically isolated $\mathrm{Ca}^{2+}$ current from the $\mathrm{IHC}$ are shown in top and middle traces, individual postsynaptic responses in bottom traces $\left(I_{\text {post }}\right)$. $\boldsymbol{A}$, The IHC was briefly depolarized with a step from $-89 \mathrm{mV}$ to $-29 \mathrm{mV}$ for $2 \mathrm{~ms}$ (test pulse). This command evoked a presynaptic $\mathrm{Ca}^{2+}$ current and synaptic currents at the postsynaptic terminal. In $\sim 47 \%$ of the test pulses, synaptic failures were observed. $\boldsymbol{B}$, The IHC membrane potential was held at a more positive potential $(-49 \mathrm{mV})$ for $50 \mathrm{~ms}$ (predepolarization) and then depolarized to $-29 \mathrm{mV}$ for $2 \mathrm{~ms}$, leading to an enhanced postsynaptic response. No failures were observed in response to test pulses after pre-depolarization.

aptic responses in afferent fibers were monitored in parallel. In this preparation, about a dozen auditory nerve fibers contact one IHC, and each afferent fiber receives input from only one IHC through a single, unbranched dendrite (Liberman, 1980, 1982).

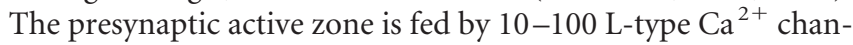
nels with very low maximum open probability $(0.15-0.4)$ (Rodriguez-Contreras and Yamoah, 2001; Brandt et al., 2005; Zampini et al., 2010). Therefore, while IHC $\mathrm{Ca}^{2+}$ currents recorded in the whole-cell configuration include channels activated at all synaptic contacts, the recorded postsynaptic response corresponds to the activity at a single presynaptic active zone (a single ribbon synapse) and the stochastic gating of a subset of the hair cell $\mathrm{Ca}^{2+}$ channels.

In a first set of experiments, IHCs were depolarized for $2 \mathrm{~ms}$ from $-89 \mathrm{mV}$ to $-29 \mathrm{mV}$ (test depolarization) (Fig. 1). $\mathrm{Ca}^{2+}$ currents activated fully (see Fig. 4 for further details) and the postsynaptic response showed a high failure rate of 47\% (47 \pm $14 \%, n=6$ cell pairs, $5-56$ repetitions each) (Fig. $1 A$ ). Successful postsynaptic responses varied in amplitude with an average size of $177 \pm 32 \mathrm{pA}$ ( $n=6$ cell pairs, $7-52$ repetitions each, ) and EPSC waveforms often showed inflections (Fig. $1 A$ ), most likely due to incompletely coordinated release of multiple vesicles (Glowatzki and Fuchs, 2002). When the IHC was pre-depolarized from $-89 \mathrm{mV}$ to $-49 \mathrm{mV}$ for $50 \mathrm{~ms}$, the probability of release increased to 1 during the test depolarization, and the average EPSC amplitude increased about twofold $(375 \pm 41 \mathrm{pA}, n=4$ cell pairs, $7-9$ repetitions each, $p=0.006$ ) (Fig. $1 B$ ).

Next, we tested how the duration of the pre-depolarizing step affects the synaptic response. As we will show in Figure $5, \mathrm{Ca}^{2+}$ influx is required for the conditioning effect induced by predepolarization. However, the size of the $\mathrm{Ca}^{2+}$ current in response to depolarization varies among individual recordings. Therefore, to allow for comparison between recordings, we adjusted the experimental conditions for individual recordings to keep the size of the $\mathrm{Ca}^{2+}$ currents during pre-depolarization within a narrow range of $25-60 \mathrm{pA}$ ( $45 \pm 5 \mathrm{pA}, n=6$ cell pairs). This was achieved by setting the holding potential for pre-depolarization in individual recordings to values between $-55 \mathrm{mV}$ and $-49 \mathrm{mV}$. As 
shown previously, at $-89 \mathrm{mV}$ we observed very few EPSCs (Goutman and Glowatzki, 2007), but during predepolarization to $-55 /-49 \mathrm{mV}$, the rate of release increased to $35 \pm 9$ EPSCs/s, consistent with the idea that $\mathrm{Ca}^{2+}$ is entering the IHC at these potentials. At $-55 /$ $-49 \mathrm{mV}$, multivesicular EPSCs were found with average amplitudes of $100 \pm$ $12 \mathrm{pA}$, similar to values from our earlier studies (Goutman and Glowatzki, 2007).

For the test depolarization, to activate maximal release in all recordings, the holding potential was set to values between $-29 \mathrm{mV}$ and $-9 \mathrm{mV}$. In summary, pre-depolarization pulses to $-49 /-55$ $\mathrm{mV}$ of variable length $(0,1,5,10,25$, and $50 \mathrm{~ms}$ ) were applied to individual IHCs followed by $2 \mathrm{~ms}$ test depolarizations to $-29 /-9 \mathrm{mV}$ (Fig. 2). Without predepolarization, the average EPSC amplitude in response to the test pulse was $143 \pm 29 \mathrm{pA}$ (including failures, $n=6$ cell pairs, 5-8 repetitions each). Transmitter release increased significantly with predepolarization, reaching a maximum at a pre-depolarization of $50 \mathrm{~ms}$ with an average amplitude of $333 \pm 35 \mathrm{pA}$, representing a $\sim 2.8 \pm 0.7$-fold increase $(n=6$ cell pairs; ANOVA, $p=0.00018$ ) (Fig. $2 B$ ).

A closer analysis of the experiments shown in Figures 1 and 2 indicated that in addition to increased release, postsynaptic responses activated after shorter delays when longer pre-depolarizations preceded the test pulse (Fig. $2 C-E$ ). Without pre-depolarization, the synaptic delay measured from the beginning of the test depolarization to the onset of the EPSC was $3.38 \pm 0.44 \mathrm{~ms}$ ( $n=6$ cell pairs, $5-8$ repetitions each) (Fig. $2 C$ ). With pre-depolarizations ( $5 \mathrm{~ms}$ and longer), synaptic delays became significantly shorter (Fig. $2 E$ ), reaching a minimum at a $25 \mathrm{~ms}$ pre-depolarization with a delay of $1.48 \pm$ $0.04 \mathrm{~ms}(n=6$, ANOVA $p<0.0001)$ (Fig. $2 D)$.

In summary, both the probability of release and the synaptic delay in response to a test pulse were affected by pre-depolarization, suggesting that a common mechanism may underlie both these changes. Also, these results raise the possibility that synaptic responses at the IHC ribbon synapse may be modulated by changes in the preceding IHC resting membrane potential.

\section{Synaptic responses to longer test depolarizations are also conditioned by pre-depolarization}

The 2 ms test depolarizations used in Figure 2 resulted in low success rates for synaptic events, allowing for positive modulation to occur. For comparison, we investigated the effect of the preceding IHC membrane potential on stimuli with a high probability of release. Stimulation protocols with longer test depolarizations were used ( $10 \mathrm{~ms}$, from -89 to $-29 \mathrm{mV}$ ), resulting in $100 \%$ success rates. During the $10 \mathrm{~ms}$ test depolarization, the postsynaptic response reached its peak amplitude of $438 \pm 71 \mathrm{pA}$ ( $n=5$ cell pairs, 4 - 6 repetitions each) (Fig. $3 A$ ) followed by synaptic depression as described earlier (Goutman and Glowatzki, 2007). When pre-depolarizations to $-49 /-55 \mathrm{mV}$ were applied at different durations ( 1 to $50 \mathrm{~ms}$ ), no change in the EPSC amplitude in response to the test depolarization was found (ANOVA for the six different conditions, $p>0.05$ ) (Fig. $3 B$ ). As the peak of the response typically occurs within the first $10 \mathrm{~ms}$ and its voltage dependence shows saturation at $-29 \mathrm{mV}$, this result was expected. However, we did observe an improvement in synaptic delay for postsynaptic responses to longer predepolarizations. When preholding the IHC membrane potential at $-89 \mathrm{mV}$, the postsynaptic response to the test pulse had a delay of $4.76 \pm 0.46 \mathrm{~ms}$ ( $n=5$ cell pairs $)$. This delay is slightly longer compared to the synaptic delay in response to $2 \mathrm{~ms}$ test depolarizations ( $3.38 \pm 0.44 \mathrm{~ms})$. This difference may arise because some release events may fail to activate with weak stimuli ( $2 \mathrm{~ms})$, but in the case of long pulses and hence stronger stimulation, they may occur only after a longer delay. Significant reductions in synaptic delay of $\sim 50 \%$ occurred at 25 and $50 \mathrm{~ms}$ pre-depolarization, with values of $2.42 \pm 0.13$ and $2.49 \pm 0.12 \mathrm{~ms}$, respectively $(n=$ 5 cell pairs; ANOVA $p<0.001$ ) (Fig. $3 C$ ).

Together, these observations indicate that pre-depolarization produces conditioning of transmitter release for synaptic responses occurring with low and high success rates.

\section{Contribution of changes in $\mathrm{Ca}^{2+}$ current to conditioning of transmitter release}

For CNS synapses it has been shown that in response to repeated stimuli, $\mathrm{Ca}^{2+}$ currents can facilitate and in turn contribute to facilitation of transmitter release (Inchauspe et al., 2004; Mochida et al., 2008; Muller et al., 2008). We therefore analyzed whether the IHC $\mathrm{Ca}^{2+}$ currents in response to test pulses were affected by pre-depolarization (Fig. 4). Sample traces of $\mathrm{Ca}^{2+}$ currents in response to $2 \mathrm{~ms}$ test pulses are shown in 

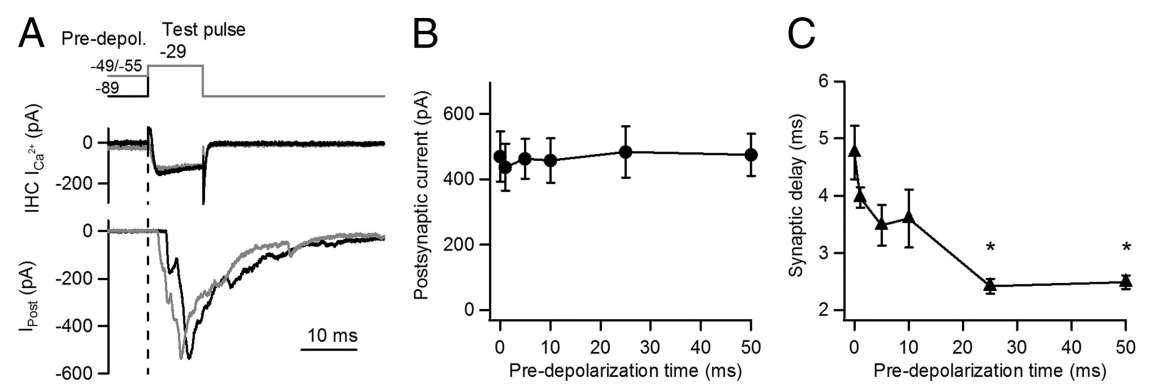

Figure 3. Postsynaptic responses to long test pulses present shorter synaptic delays after pre-depolarization. $A$, IHC $\mathrm{Ca}^{2+}$ currents and postsynaptic responses activated by $10 \mathrm{~ms}$ test pulses, either with no pre-depolarization (black traces) or preceded by a 25 ms pre-depolarization (gray traces). $\boldsymbol{B}$, Average postsynaptic response ( $n=5$ cell pairs) obtained with different predepolarization times. C, Summary plot of synaptic delay (measured from the onset of the test pulse to the onset of the synaptic response) in response to at test pulse after different durations of pre-depolarization. ${ }^{*} p<0.05$.
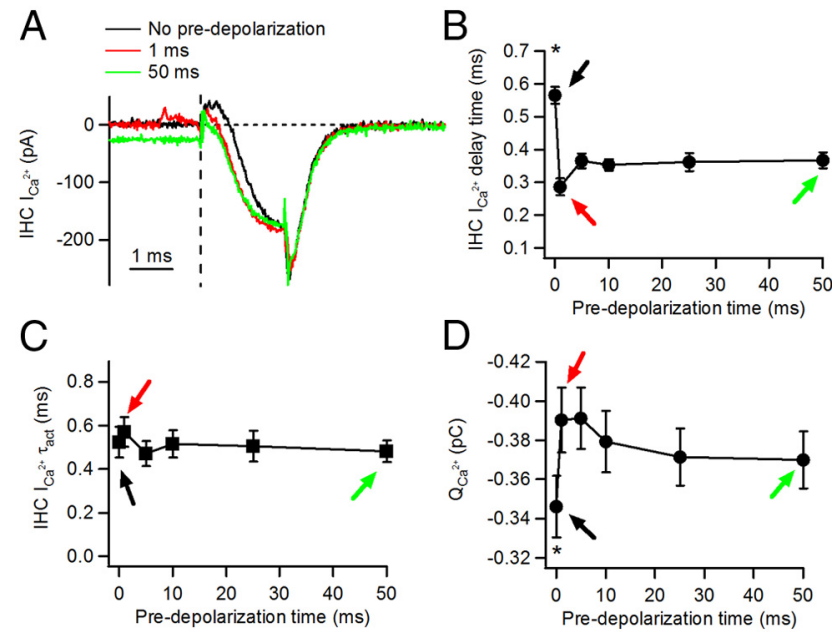

Figure 4. Changes of the presynaptic $\mathrm{IHC} \mathrm{Ca}^{2+}$ current by pre-depolarizations. A, Average $\mathrm{Ca}^{2+}$ current traces for $2 \mathrm{~ms}$ depolarizations to $-29 \mathrm{mV}$ starting from $-89 \mathrm{mV}$ (no predepolarization) or after pre-depolarizations of 1 or $50 \mathrm{~ms}$. B, Delay to $\mathrm{Ca}^{2+}$ current activation, calculated from the onset of the test pulse, as a function of pre-depolarization duration. Black, red, and green arrows indicate $\mathrm{I}_{\mathrm{Ca}^{2+}}{ }^{2+}$ parameters after 0,1 , and 50 ms pre-depolarizations, respectively. C, Activation time constant $\tau_{\text {act }}$ of $\mathrm{Ca}^{2+}$ currents. $^{*} p<0.05 . \boldsymbol{D}, \mathrm{Ca}^{2+}$ charge $\mathrm{Q}_{\mathrm{Ca}}{ }^{2+} \cdot \mathrm{Ca}^{2+}$ charge was calculated as the integral of the $\mathrm{Ca}^{2+}$ current during the $2 \mathrm{~ms}$ test depolarization.

Figure $4 A \cdot \mathrm{Ca}^{2+}$ currents activated without pre-depolarization (black trace) showed an obvious difference in time course compared to $\mathrm{Ca}^{2+}$ currents activated with pre-depolarization ( 1 and $50 \mathrm{~ms}$, red and green traces, respectively). As an estimate of the $\mathrm{Ca}^{2+}$ current activation, we measured the delay time between the beginning of the test pulse and the onset of the $\mathrm{Ca}^{2+}$ current (see Materials and Methods). Figure $4 B$ shows how this delay time depends on pre-depolarization time. $\mathrm{Ca}^{2+}$ currents that were not preceded by a pre-step showed longer delay times $(0.57 \pm 0.03 \mathrm{~ms}$, $n=6$ cell pairs, $5-8$ repetitions each, ANOVA $p<0.05)$. Even after a brief $1 \mathrm{~ms}$ pre-depolarization, $\mathrm{Ca}^{2+}$ currents activated significantly faster, similar to $\mathrm{Ca}^{2+}$ currents occurring in response to longer pre-depolarizations ( $1 \mathrm{~ms}$ : $0.29 \pm 0.03 \mathrm{~ms} ; 50$ ms: $0.37 \pm 0.03 \mathrm{~ms}$; ANOVA $p>0.05, n=6$ cell pairs; for an explanation of a possible underlying mechanism, see Discussion). To investigate whether $\mathrm{Ca}^{2+}$ current kinetics were affected, we performed an exponential fit of the activation phase. No differences in the time constant of activation were found regardless of the duration of the pre-depolarization (no pre-depolarization: $0.52 \pm 0.08 \mathrm{~ms}$; $50 \mathrm{~ms}$ : $0.48 \pm 0.05 \mathrm{~ms}$; ANOVA, $p=0.93$ ) (Fig.
$4 C)$. As a measure of $\mathrm{Ca}^{2+}$ influx into the cell, the integral of the $\mathrm{Ca}^{2+}$ currents (the charge) in response to the test pulse was computed (see Materials and Methods). The $\mathrm{Ca}^{2+}$ charge for test pulses with no pre-depolarization was $0.35 \pm 0.01 \mathrm{pC}$, whereas a significant 1.07- to 1.13-fold increase was observed when using any duration of pre-depolarization (1 ms: $0.39 \pm$ 0.02 pC (1.13-fold); $50 \mathrm{~ms}: 0.37 \pm 0.02$ pC (1.07-fold); $n=6$ cell pairs each protocol, ANOVA $p<0.0001$ ) (Fig. $4 D$ ).

Next, we evaluated whether these differences in $\mathrm{Ca}^{2+}$ charge could contribute to the significant changes in transmitter release. Assuming a power relationship between $\mathrm{Ca}^{2+}$ influx and transmitter release with an exponent of 3-4, the increased $\mathrm{Ca}^{2+}$ charge in protocols with pre-depolarization could at most account for $\sim$ $33 \%$ of the facilitation in transmitter release $\left(1.13^{4}\right.$ equals a 1.6fold increase compared to a 2.8-fold actual increase) (Fig. 2). Nonetheless, it has been proposed that the relation between $\mathrm{Ca}^{2+}$ influx and IHC transmitter release is linear when evoked at negative potentials (Brandt et al., 2005; Johnson et al., 2005; Goutman and Glowatzki, 2007), suggesting an even smaller contribution of the $\mathrm{Ca}^{2+}$ charge increase to facilitation of transmitter release. All this suggests that an additional mechanism must contribute to produce the amount of conditioning of transmitter release for test pulses without pre-depolarization compared to test pulses with pre-depolarization.

In addition to this line of reasoning, we also showed that $\mathrm{Ca}^{2+}$ current characteristics were indistinguishable among experiments with different durations of pre-depolarization (Fig. $4 A-$ $D)$. However, synaptic responses after $50 \mathrm{~ms}$ pre-depolarization compared to $1 \mathrm{~ms}$ depolarization were significantly larger (ANOVA, Tukey as post hoc test, $p<0.01$ ). Similarly, synaptic delays after 25 and $50 \mathrm{~ms}$ pre-depolarization compared to $1 \mathrm{~ms}$ pre-depolarization were significantly shorter (ANOVA, Tukey as post hoc test, $p<0.0001)$. These results also suggest that the changes in synaptic release that occur in response to varying the duration of the pre-depolarization rely on a mechanism that is different from $\mathrm{Ca}^{2+}$ current facilitation and most likely occurs downstream of $\mathrm{Ca}^{2+}$ entry.

\section{$\mathrm{Ca}^{2+}$ influx is required during pre-depolarization to induce synaptic conditioning}

Synaptic conditioning depends on the duration of predepolarization, suggesting that either $\mathrm{Ca}^{2+}$ influx might be responsible for this effect or, alternatively, that pre-depolarization per se might be required. To distinguish between these two options, a voltage step protocol was designed to minimize $\mathrm{Ca}^{2+}$ influx during pre-depolarization. In control experiments, predepolarization steps to $-49 /-55 \mathrm{mV}$ were applied for $25 \mathrm{~ms}$, and transmitter release was triggered by a $\mathrm{Ca}^{2+}$ tail current that activated in response to repolarization of the IHC membrane potential from +71 to $-89 /-129 \mathrm{mV}$ (Fig. 5A). EPSCs activated by $\mathrm{Ca}^{2+}$ tail currents had amplitudes of $158 \pm 21 \mathrm{pA}$ (Fig. $5 A$ ) and a success rate of $0.89 \pm 0.20$ ( $n=4$ cell pairs, $3-16$ repetitions). The synaptic delay measured from the time of repolarization was $1.22 \pm 0.11 \mathrm{~ms}$, even shorter compared to the synaptic delay in response to $2 \mathrm{~ms}$ depolarizing test pulses to $-29 \mathrm{mV}$ after $25 \mathrm{~ms}$ pre-depolarization (Fig. $2 \mathrm{~B}$ ). When $\mathrm{Ca}^{2+}$ influx was minimized by stepping directly to $71 \mathrm{mV}$ instead of pre-depolarizing to -49 / 
$-55 \mathrm{mV}$, no synaptic responses were activated upon repolarization to $-89 \mathrm{mV}$ ( $n=4$ cell pairs) (Fig. $5 B$ ). However, the $\mathrm{Ca}^{2+}$ tail currents compared to the control experiment were similar in size (pre-depolarization to $71 \mathrm{mV}: 311 \pm 70$ pA; 25 ms pre-depolarization to -49 / $-55 \mathrm{mV}: 300 \pm 73 \mathrm{pA} ; n=4$ cell pairs; $t$ test, $p=0.09)$. These experiments indicate that pre-depolarization is insufficient by itself, but that $\mathrm{Ca}^{2+}$ influx is required during pre-depolarization to condition transmitter release.

\section{Paired-pulse facilitation}

Our observation that $\mathrm{Ca}^{2+}$ influx preceding a test stimulus can condition neurotransmitter release at the IHC ribbon synapse is reminiscent of mechanisms underlying short-term facilitation at CNS synapses (Zucker and Regehr, 2002). We therefore tested whether a paired-pulse protocol might induce facilitation at the IHC ribbon synapse.

Two $2 \mathrm{~ms}$ stimuli (S1 and S2) were applied to depolarize the IHC from -89 to $-29 \mathrm{mV}$, with various interstimulus intervals (ISIs) ranging from $10 \mathrm{~ms}$ to $2 \mathrm{~s}$ (Fig. 6). The short stimuli ensured nonsaturating probability of release, allowing for positive modulation. Similar to the results presented in Figure 2, the postsynaptic response to $\mathrm{S} 1$ had a low probability of release, $0.56 \pm$ 0.11 ( $n=5$ cell pairs, 40 depolarizations $)$ and an EPSC amplitude of $123 \pm 37 \mathrm{pA}$ (including failures) (Fig. 6A). S2, compared to S1, elicited a facilitated synaptic response. The largest amount of facilitation was found at an ISI of $100 \mathrm{~ms}$ with an $\sim 5$-fold increase in the paired-pulse ratio (R2/R1) of the synaptic response (491 $\pm 190 \%)$, ranging between 229 and $1236 \%(n=5$ cell pairs, $5-9$ repetitions each) (Fig. $6 B$ ). This effect decayed for longer ISIs with a time constant of $659 \pm 236 \mathrm{~ms}(n=5)$. As expected, a lower probability of release in response to $S 1$ resulted in a higher level of facilitation in response to S2 (data not shown).

Reminiscent of the results with pre-depolarization, a change in the synaptic delay also occurred with paired-pulse facilitation. In response to $\mathrm{S} 1$, the synaptic delay was $3.68 \pm 0.34 \mathrm{~ms}(n=5$ cell pairs, 40 depolarizations), whereas in response to $S 2$ at 10 and $100 \mathrm{~ms}$ ISI, synaptic delays were $2.43 \pm 0.15 \mathrm{~ms}$ and $2.32 \pm 0.09$ ms, respectively ( $n=5$ cell pairs, $5-9$ repetitions each; ANOVA, $p=0.01$ ) (Fig. 6C). For ISIs $>100 \mathrm{~ms}$ the synaptic delay increased again, and for ISIs of $500 \mathrm{~ms}$ and higher it reached values not different from responses to S1 (ANOVA, $p>0.05$ ). In summary, responses of the IHC afferent synapse to a paired-pulse protocol showed facilitation and shortening of the synaptic delay, both with a maximal effect at an ISI of $100 \mathrm{~ms}$.

Finally, $\mathrm{Ca}^{2+}$ currents were also analyzed for paired-pulse experiments. The average $\mathrm{Ca}^{2+}$ charge in response to $\mathrm{S} 1$ was $0.25 \pm 0.03 \mathrm{pC}$ ( $n=5$ cell pairs, $n=40$ depolarizations). A small but significant increase in $\mathrm{Ca}^{2+}$ charge was found at ISIs of 100 and $250 \mathrm{~ms}$ (maximal 1.04-fold of $0.26 \pm 0.02 \mathrm{pC}$ and 1.05-fold of $0.26 \pm 0.03 \mathrm{pC}$, respectively; $n=5$ cell pairs; ANOVA, $p<$ $0.05)$. These changes in $\mathrm{Ca}^{2+}$ charge were paralleled by an increase in $\mathrm{Ca}^{2+}$ current amplitude (Fig. 6D), but no differences were observed in activation kinetics (data not shown). If, again, we assume a relationship between $\mathrm{Ca}^{2+}$ influx and transmitter release with a power of 1-4 (Brandt et al., 2005; Johnson et al., 2005; Goutman and Glowatzki, 2007), the maximal synaptic fa- cilitation that could be caused by $\mathrm{Ca}^{2+}$ current facilitation would be $\sim 1.22$-fold and could support only a very small fraction of the 5 -fold paired-pulse facilitation measured at an ISI of $100 \mathrm{~ms}$. Therefore, an additional mechanism other than $\mathrm{Ca}^{2+}$ current facilitation must mostly support paired-pulse facilitation at the IHC ribbon synapse.

\section{Discussion}

\section{Short-term plasticity at the IHC afferent synapse}

Auditory nerve fibers adapt in response to sound signals presented with constant intensity (Galambos and Davis, 1943; Kiang et al., 1965). The main underlying mechanisms for auditory nerve adaptation is most likely synaptic depression at the IHC ribbon synapse caused by the exhaustion of presynaptic vesicles ready for release (Furukawa and Matsuura, 1978; Moser and Beutner, 2000; Spassova et al., 2004; Johnson et al., 2005; Schnee et al., 2005; Goutman and Glowatzki, 2007; Li et al., 2009). Some depressing synapses in the CNS and at the neuromuscular junction have been shown to facilitate in conditions of low release probability. Facilitation can be unmasked in paired-pulse protocols by manipulating the extracellular $\mathrm{Ca}^{2+}$ concentration (Katz and Miledi, 1968; Charlton and Bittner, 1978) or by reducing the time of presynaptic depolarization (Felmy et al., 2003). In the present study, short-term facilitation at the IHC ribbon synapse was revealed when short paired pulses were applied to the IHC or when the IHC was pre-depolarized to voltages of -55 to $-49 \mathrm{mV}$, thereby inducing $\mathrm{Ca}^{2+}$ influx and preconditioning for enhanced release during a test pulse.

Regarding the underlying mechanisms for short-term facilitation, early observations of Katz and Miledi at the neuromuscular junction suggested that paired-pulse facilitation depends on the continued elevation of residual $\mathrm{Ca}^{2+}$ in the presynaptic terminal after the first stimulus (Katz and Miledi, 1968). This observation was later generalized to many vertebrate and nonvertebrate synapses (Zucker and Regehr, 2002). Nonetheless, more recent studies suggest that the residual $\mathrm{Ca}^{2+}$ concentration cannot completely account for a $\sim 2$-fold increase in the probability of release (Felmy et al., 2003). Additional mechanisms have been proposed to complement the residual $\mathrm{Ca}^{2+}$ hypothesis: (1) the existence of a "facilitation site" with an additional high affinity $\mathrm{Ca}^{2+}$ binding site that triggers facilitation upon $\mathrm{Ca}^{2+}$ binding 
A
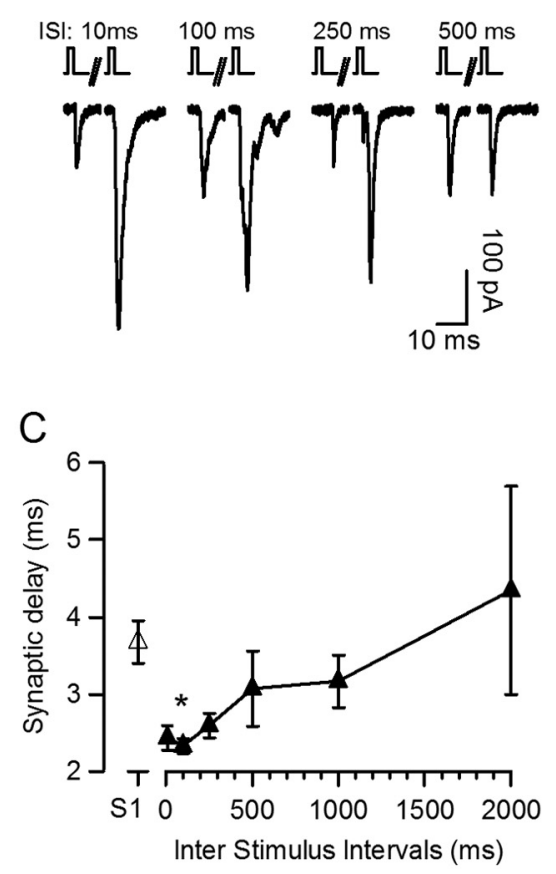

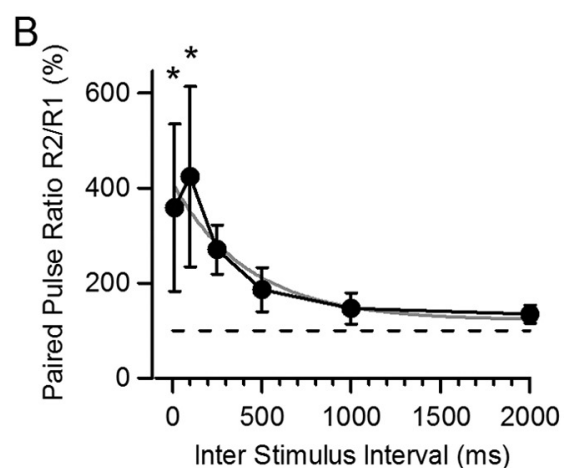

D

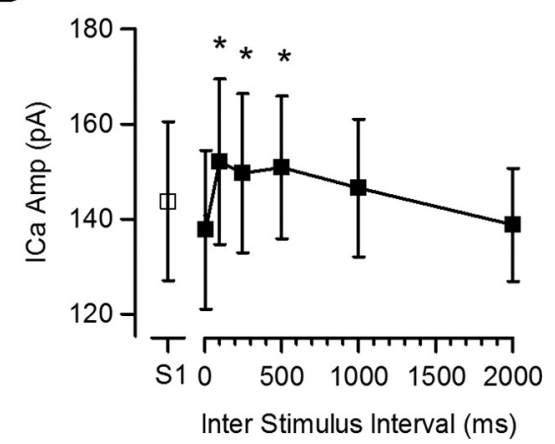

Figure 6. Paired-pulse facilitation at the IHC ribbon synapse. $\boldsymbol{A}$, Paired-pulse protocol was tested with brief 2 ms depolarizations from $-89 \mathrm{mV}$ to $-29 \mathrm{mV}$ and interstimulus intervals ranging from $10 \mathrm{~ms}$ to $2 \mathrm{~s}$. Exemplar traces of single postsynaptic responses to the first (S1) and second stimulus (S2) for representative ISIs. B, Paired-pulse ratio R2/R1 of the postsynaptic responses at different ISIs for six cell pairs. Broken line represents average amplitude of $\$ 1$. Monoexponential fit of paired-pulse facilitation decay is shown in gray. C, Synaptic delay of postsynaptic responses to S1 (open triangle) or S2 (closed triangles) at different ISIs. D, Amplitude of Ca ${ }^{2+}$ currents for S1 (open square) and S2 at different ISIs (filled square). ${ }^{*} p<0.05$.

(Atluri and Regehr, 1996; Tang et al., 2000); (2) $\mathrm{Ca}^{2+}$ buffer saturation following the first stimulus resulting in a nonlinear increase in $\mathrm{Ca}^{2+}$ concentration (Rozov et al., 2001); and (3) $\mathrm{Ca}^{2+}$ current facilitation resulting in facilitation of transmitter release because of increased $\mathrm{Ca}^{2+}$ influx (Borst and Sakmann, 1998; Cuttle et al., 1998; Xu et al., 2007; Muller et al., 2008).

Besides its crucial role in exocytosis, presynaptic $\mathrm{Ca}^{2+}$ can affect priming of synaptic vesicles by binding to calmodulin, promoting calmodulin's binding to Munc13, and thereby determining the size of the readily releasable pool of vesicles (Junge et al., 2004). After depletion, presynaptic $\mathrm{Ca}^{2+}$ is also involved in the process of recovery of the readily releasable pool (Stevens and Wesseling, 1998; Wang and Kaczmarek, 1998; Dittman et al., 2000; Hosoi et al., 2007; Neher and Sakaba, 2008).

Here, we show that similar mechanisms may underlie facilitation of transmitter release at the IHC ribbon synapse. First, facilitation is unmasked using short stimuli, which induce responses with a low probability of release. Second, $\mathrm{Ca}^{2+}$ influx is required during the conditioning stimulus to induce facilitation. However, the experiments presented here cannot discriminate whether $\mathrm{Ca}^{2+}$ accumulation or other $\mathrm{Ca}^{2+}$-dependent presynaptic mechanisms are responsible for inducing facilitation. Third, $\mathrm{Ca}^{2+}$ current facilitation occurs and can account in part for facilitation of transmitter release. For CNS synapses, there has been some debate on whether $\mathrm{Ca}^{2+}$ current facilitation is the main factor responsible for transmitter release facilitation (Inchauspe et al., 2004; Xu et al., 2007) or whether it has a limited role (Muller et al., 2008). At the hair cell ribbon synapse, we found that $\mathrm{Ca}^{2+}$ current facilitation is a minor contributor to transmitter release facilitation. If we assume that the $\mathrm{Ca}^{2+}$ dependence of release follows a power relation with an exponent between 1 and 4 (Brandt et al., 2005; Johnson et al., 2005; Goutman and Glowatzki, 2007), $\mathrm{Ca}^{2+}$ current facilitation can maximally explain $5 \%$ of the paired-pulse facilitation and the increase in $\mathrm{Ca}^{2+}$ charge can account for maximally 33\% of the facilitation in response to predepolarization. Fourth, the decay of paired-pulse facilitation with longer interstimulus intervals occurred with a time constant of $659 \mathrm{~ms}$ (Fig. $6 \mathrm{~B}$ ), similar to other chemical synapses: for example, synapses in microcultures of rat hippocampal neurons ( $\tau=380 \mathrm{~ms}$ ) (Mennerick and Zorumski, 1995) or the synapse between granule cell and Purkinje cell $(\tau=200)$ (Atluri and Regehr, 1996).

Recent studies have shown that steady subthreshold depolarizations on the neuronal soma or directly on calyceal presynaptic terminals induce an increase in action potential-evoked release (Awatramani et al., 2005; Christie et al., 2011). Similar to our predepolarization-induced conditioning, this effect is dependent on $\mathrm{Ca}^{2+}$ influx, but through $\mathrm{P} / \mathrm{Q}$ type $\mathrm{Ca}^{2+}$ channels.

\section{$\mathrm{Ca}^{2+}$ current facilitation}

In short-term plasticity protocols, $\mathrm{Ca}^{2+}$ current facilitation is mediated by calmodulin, which requires the binding of $\mathrm{Ca}^{2+}$ and plays a role both in mediating facilitation and inactivation of $\mathrm{Ca}^{2+}$ channels (Peterson et al., 1999; DeMaria et al., 2001). In our paired-pulse experiments, we find larger $\mathrm{Ca}^{2+}$ current amplitudes, resulting in larger $\mathrm{Ca}^{2+}$ charges in response to some ISIs. It seems reasonable to assume that this $\mathrm{Ca}^{2+}$ current facilitation is mediated by such a calmodulin-dependent mechanism, as calmodulin is also involved in $\mathrm{Ca}^{2+}$ current inactivation in IHCs (Grant and Fuchs, 2008). However, it is less likely that such a mechanism can underlie the faster activation of $\mathrm{Ca}^{2+}$ currents found in the predepolarization experiments. Here, a larger $\mathrm{Ca}^{2+}$ charge is observed, even after $1 \mathrm{~ms}$ pre-depolarization, which would be unlikely to drive sufficient $\mathrm{Ca}^{2+}$ influx to trigger calmodulindependent processes.

Alternatively, it should also be considered that voltage jumps starting at the $-49 /-55 \mathrm{mV}$ would reach $-29 /-9 \mathrm{mV}$ earlier than those starting from $-89 \mathrm{mV}$. Accordingly, voltage-dependent conductances, such as the $\mathrm{Ca}^{2+}$ currents we show in Figure 4, would activate faster. A similar phenomenon could occur in a physiological context where the IHC receptor potential, driven by the mechano-transduction current, may undergo faster depolarizing transitions because of this slightly elevated resting membrane potential.

\section{Synaptic delay changes with facilitation}

A key observation in our study is that synaptic latency was shortened (2-3 times maximally) during paired-pulse facilitation or after pre-depolarization. In both experimental protocols, the postsynaptic response increased and synaptic latency decreased. Longer, 10 ms test pulses activated synaptic currents maximally, 
and therefore pre-depolarizations did not further enhance these responses. However, for $10 \mathrm{~ms}$ test pulses also, shorter synaptic delays after longer pre-depolarizations still did occur.

Reduced synaptic latency associated with facilitation has been reported at other synapses, for example at the crayfish neuromuscular junction (Vyshedskiy and Lin, 1997) and in reciprocal synapses of pyramidal neurons in hippocampus and cortex (Boudkkazi et al., 2007). It has also been shown recently that synaptic delay is inversely correlated with the probability of release at retinal ribbon synapses (Jarsky et al., 2010).

Regarding possible mechanisms underlying the shortened latency of the facilitated response in IHCs, one could propose that the same processes that mediate the size increase (see Short-term plasticity at the IHC afferent synapse, above) could also be responsible for the change in latency. An alternative explanation could include the state of $\mathrm{Ca}^{2+}$ binding of the IHC $\mathrm{Ca}^{2+}$ sensor. Even though the identity of the $\mathrm{Ca}^{2+}$ sensor in hair cells is still under discussion (Safieddine and Wenthold, 1999; Roux et al., 2006; Beurg et al., 2010; Johnson and Chapman, 2010; Johnson et al., 2010; Pangrsic et al., 2010), it is clear from experiments using flash photolysis that it is highly cooperative, requiring the binding of $\sim 5 \mathrm{Ca}^{2+}$ ions to trigger release (Beutner et al., 2001). At $-89 \mathrm{mV}$, with minimal $\mathrm{Ca}^{2+}$ influx into the IHC and a low ambient intracellular $\mathrm{Ca}^{2+}$ concentration, the great majority of binding sites on the $\mathrm{Ca}^{2+}$ sensor may be unbound. When a stimulus arrives, the $\mathrm{Ca}^{2+}$ sensor may need to go through all intermediate states (partially $\mathrm{Ca}^{2+}$-bound), imposing a delay before release can occur. However, during pre-depolarization, $\mathrm{Ca}^{2+}$ influx may cause frequent $\mathrm{Ca}^{2+}$ bindings to the sensor, favoring intermediate $\mathrm{Ca}^{2+}$ bound states closer toward "fusionreadiness." This could result in shorter latencies of the synaptic response. Simulating our experimental situation with a $\mathrm{Ca}^{2+}$ sensor model and parameters as described by Beutner et al. (2001) confirmed this trend to shorter latencies after predepolarization (data not shown).

\section{Coding of acoustic signals at the IHC afferent synapse}

How do the experiments presented in this study relate to the performance of the IHC afferent synapse in vivo? In the adult guinea pig in vivo, the IHC resting membrane potential has been reported at approximately $-40 \mathrm{mV}$ with sharp electrode recordings (Russell and Sellick, 1978). However, leakiness of these technically quite difficult recordings cannot be excluded. In vitro patch-clamp recordings report more negative IHC resting membrane potentials (Kros and Crawford, 1990; Marcotti et al., 2003); however, due to the artificial composition of intracellular and extracellular solutions, these measurements may not represent the in vivo situation well. The best estimate of the IHC resting membrane potential in vivo may be based on the observation that spontaneous firing of auditory nerve fibers depends on the activation of L-type $\mathrm{Ca}^{2+}$ channels (Robertson and Paki, 2002). The IHC resting membrane potential is therefore most likely more positive than the activation threshold of L-type $\mathrm{Ca}^{2+}$ channels that has been reported at about -60 to $-50 \mathrm{mV}$ (Brandt et al., 2005; Johnson et al., 2005; Grant and Fuchs, 2008). Our study demonstrates that the relatively positive resting membrane potential of IHCs may have additional physiological relevance. We show that pre-depolarization to potentials around $-55 /-49 \mathrm{mV}$ increased the probability of release and improved timing at the IHC ribbon synapse. We propose that $\mathrm{Ca}^{2+}$ influx at rest may shift the operating mode of the IHC into a constantly facilitated mode that allows for a larger and faster synaptic response during depolarization. For future experiments in vitro, it may be advis- able to use more positive holding potentials rather than -90 or $-80 \mathrm{mV}$ for more realistic estimates of size and timing of the recorded synaptic responses.

\section{References}

Atluri PP, Regehr WG (1996) Determinants of the time course of facilitation at the granule cell to Purkinje cell synapse. J Neurosci 16:5661-5671.

Awatramani GB, Price GD, Trussell LO (2005) Modulation of transmitter release by presynaptic resting potential and background calcium levels. Neuron 48:109-121.

Beurg M, Michalski N, Safieddine S, Bouleau Y, Schneggenburger R, Chapman ER, Petit C, Dulon D (2010) Control of exocytosis by synaptotagmins and otoferlin in auditory hair cells. J Neurosci 30:13281-13290.

Beutner D, Voets T, Neher E, Moser T (2001) Calcium dependence of exocytosis and endocytosis at the cochlear inner hair cell afferent synapse. Neuron 29:681-690.

Borst JG, Sakmann B (1998) Facilitation of presynaptic calcium currents in the rat brainstem. J Physiol 513:149-155.

Boudkkazi S, Carlier E, Ankri N, Caillard O, Giraud P, Fronzaroli-Molinieres L, Debanne D (2007) Release-dependent variations in synaptic latency: a putative code for short- and long-term synaptic dynamics. Neuron 56:1048-1060.

Brandt A, Khimich D, Moser T (2005) Few CaV1.3 channels regulate the exocytosis of a synaptic vesicle at the hair cell ribbon synapse. J Neurosci 25:11577-11585.

Charlton MP, Bittner GD (1978) Facilitation of transmitter release at squid synapses. J Gen Physiol 72:471-486.

Christie JM, Chiu DN, Jahr CE (2011) Ca(2+)-dependent enhancement of release by subthreshold somatic depolarization. Nat Neurosci 14:62-68.

Cuttle MF, Tsujimoto T, Forsythe ID, Takahashi T (1998) Facilitation of the presynaptic calcium current at an auditory synapse in rat brainstem. J Physiol 512:723-729.

DeMaria CD, Soong TW, Alseikhan BA, Alvania RS, Yue DT (2001) Calmodulin bifurcates the local Ca2 + signal that modulates P/Q-type Ca2+ channels. Nature 411:484-489.

Dittman JS, Kreitzer AC, Regehr WG (2000) Interplay between facilitation, depression, and residual calcium at three presynaptic terminals. J Neurosci 20:1374-1385.

Felmy F, Neher E, Schneggenburger R (2003) Probing the intracellular calcium sensitivity of transmitter release during synaptic facilitation. Neuron 37:801-811.

Fuchs PA (2005) Time and intensity coding at the hair cell's ribbon synapse. J Physiol 566:7-12.

Furukawa T, Matsuura S (1978) Adaptive rundown of excitatory postsynaptic potentials at synapses between hair cells and eight nerve fibres in the goldfish. J Physiol 276:193-209.

Galambos R, Davis H (1943) The response of single auditory nerve fiber to acoustic stimulation. J Neurophysiol 6:39-58.

Glowatzki E, Fuchs PA (2002) Transmitter release at the hair cell ribbon synapse. Nat Neurosci 5:147-154.

Goutman JD, Glowatzki E (2007) Time course and calcium dependence of transmitter release at a single ribbon synapse. Proc Natl Acad Sci U S A 104:16341-16346.

Grant L, Fuchs P (2008) Calcium- and calmodulin-dependent inactivation of calcium channels in inner hair cells of the rat cochlea. J Neurophysiol 99:2183-2193.

Hosoi N, Sakaba T, Neher E (2007) Quantitative analysis of calciumdependent vesicle recruitment and its functional role at the calyx of Held synapse. J Neurosci 27:14286-14298.

Inchauspe CG, Martini FJ, Forsythe ID, Uchitel OD (2004) Functional compensation of $\mathrm{P} / \mathrm{Q}$ by $\mathrm{N}$-type channels blocks short-term plasticity at the calyx of held presynaptic terminal. J Neurosci 24:10379-10383.

Jarsky T, Tian M, Singer JH (2010) Nanodomain control of exocytosis is responsible for the signaling capability of a retinal ribbon synapse. J Neurosci 30:11885-11895.

Johnson CP, Chapman ER (2010) Otoferlin is a calcium sensor that directly regulates SNARE-mediated membrane fusion. J Cell Biol 191:187-197.

Johnson SL, Marcotti W, Kros CJ (2005) Increase in efficiency and reduction in $\mathrm{Ca} 2+$ dependence of exocytosis during development of mouse inner hair cells. J Physiol 563:177-191.

Johnson SL, Franz C, Kuhn S, Furness DN, Rüttiger L, Münkner S, Rivolta MN, Seward EP, Herschman HR, Engel J, Knipper M, Marcotti W (2010) 
Synaptotagmin IV determines the linear $\mathrm{Ca} 2+$ dependence of vesicle fusion at auditory ribbon synapses. Nat Neurosci 13:45-52.

Junge HJ, Rhee JS, Jahn O, Varoqueaux F, Spiess J, Waxham MN, Rosenmund C, Brose N (2004) Calmodulin and Munc13 form a Ca2+ sensor/effector complex that controls short-term synaptic plasticity. Cell 118: 389-401.

Katz B, Miledi R (1968) The role of calcium in neuromuscular facilitation. J Physiol 195:481-492.

Keen EC, Hudspeth AJ (2006) Transfer characteristics of the hair cell's afferent synapse. Proc Natl Acad Sci U S A 103:5537-5542.

Kiang NY, Watanabe T, Clark LF (1965) Discharge patterns of single fibers in the cat's auditory nerve. MIT research monograph no. 35, pp 1-151. Cambridge, MA: MIT.

Kros CJ, Crawford AC (1990) Potassium currents in inner hair cells isolated from the guinea-pig cochlea. J Physiol 421:263-291.

Kros CJ, Ruppersberg JP, Rüsch A (1998) Expression of a potassium current in inner hair cells during development of hearing in mice. Nature 394:281-284.

Li GL, Keen E, Andor-Ardó D, Hudspeth AJ, von Gersdorff H (2009) The unitary event underlying multiquantal EPSCs at a hair cell's ribbon synapse. J Neurosci 29:7558-7568.

Liberman MC (1980) Morphological differences among radial afferent fibers in the cat cochlea: an electron-microscopic study of serial sections. Hear Res 3:45-63.

Liberman MC (1982) Single-neuron labeling in the cat auditory nerve. Science 216:1239-1241.

Marcotti W, Johnson SL, Holley MC, Kros CJ (2003) Developmental changes in the expression of potassium currents of embryonic, neonatal and mature mouse inner hair cells. J Physiol 548:383-400.

Mennerick S, Zorumski CF (1995) Paired-pulse modulation of fast excitatory synaptic currents in microcultures of rat hippocampal neurons. J Physiol 488:85-101.

Mochida S, Few AP, Scheuer T, Catterall WA (2008) Regulation of presynaptic $\mathrm{Ca}(\mathrm{V}) 2.1$ channels by $\mathrm{Ca} 2+$ sensor proteins mediates short-term synaptic plasticity. Neuron 57:210-216.

Moser T, Beutner D (2000) Kinetics of exocytosis and endocytosis at the cochlear inner hair cell afferent synapse of the mouse. Proc Natl Acad Sci U S A 97:883-888.

Müller M, Felmy F, Schneggenburger R (2008) A limited contribution of $\mathrm{Ca} 2+$ current facilitation to paired-pulse facilitation of transmitter release at the rat calyx of Held. J Physiol 586:5503-5520.

Neher E, Sakaba T (2008) Multiple roles of calcium ions in the regulation of neurotransmitter release. Neuron 59:861-872.

Nouvian R, Beutner D, Parsons TD, Moser T (2006) Structure and function of the hair cell ribbon synapse. J Membr Biol 209:153-165.

Pangrsic T, Lasarow L, Reuter K, Takago H, Schwander M, Riedel D, Frank T, Tarantino LM, Bailey JS, Strenzke N, Brose N, Müller U, Reisinger E, Moser T (2010) Hearing requires otoferlin-dependent efficient replenishment of synaptic vesicles in hair cells. Nat Neurosci 13:869-876.

Parsons TD, Lenzi D, Almers W, Roberts WM (1994) Calcium-triggered exocytosis and endocytosis in an isolated presynaptic cell: capacitance measurements in saccular hair cells. Neuron 13:875-883.

Peterson BZ, DeMaria CD, Adelman JP, Yue DT (1999) Calmodulin is the
$\mathrm{Ca} 2+$ sensor for $\mathrm{Ca} 2+$-dependent inactivation of L-type calcium channels. Neuron 22:549-558.

Robertson D, Paki B (2002) Role of L-type Ca2 + channels in transmitter release from mammalian inner hair cells. II. Single-neuron activity. J Neurophysiol 87:2734-2740.

Rodriguez-Contreras A, Yamoah EN (2001) Direct measurement of singlechannel $\mathrm{Ca}(2+)$ currents in bullfrog hair cells reveals two distinct channel subtypes. J Physiol 534:669-689.

Roux I, Safieddine S, Nouvian R, Grati M, Simmler MC, Bahloul A, Perfettini I, Le Gall M, Rostaing P, Hamard G, Triller A, Avan P, Moser T, Petit C (2006) Otoferlin, defective in a human deafness form, is essential for exocytosis at the auditory ribbon synapse. Cell 127:277-289.

Rozov A, Burnashev N, Sakmann B, Neher E (2001) Transmitter release modulation by intracellular $\mathrm{Ca} 2+$ buffers in facilitating and depressing nerve terminals of pyramidal cells in layer $2 / 3$ of the rat neocortex indicates a target cell-specific difference in presynaptic calcium dynamics. J Physiol 531:807-826.

Ruggero MA (1992) Physiology and coding of sound in the auditory nerve. In: The mammalian auditory pathway: neurophysiology (Popper AN, Fay RR, eds), pp 34-93. New York: Springer.

Russell IJ, Sellick PM (1978) Intracellular studies of hair cells in the mammalian cochlea. J Physiol 284:261-290.

Safieddine S, Wenthold RJ (1999) SNARE complex at the ribbon synapses of cochlear hair cells: analysis of synaptic vesicle- and synaptic membraneassociated proteins. Eur J Neurosci 11:803-812.

Schnee ME, Lawton DM, Furness DN, Benke TA, Ricci AJ (2005) Auditory hair cell-afferent fiber synapses are specialized to operate at their best frequencies. Neuron 47:243-254.

Spassova M, Eisen MD, Saunders JC, Parsons TD (2001) Chick cochlear hair cell exocytosis mediated by dihydropyridine-sensitive calcium channels. J Physiol 535:689-696.

Spassova MA, Avissar M, Furman AC, Crumling MA, Saunders JC, Parsons TD (2004) Evidence that rapid vesicle replenishment of the synaptic ribbon mediates recovery from short-term adaptation at the hair cell afferent synapse. J Assoc Res Otolaryngol 5:376-390.

Stevens CF, Wesseling JF (1998) Activity-dependent modulation of the rate at which synaptic vesicles become available to undergo exocytosis. Neuron 21:415-424.

Tang Y, Schlumpberger T, Kim T, Lueker M, Zucker RS (2000) Effects of mobile buffers on facilitation: experimental and computational studies. Biophys J 78:2735-2751.

Vyshedskiy A, Lin JW (1997) Study of the inhibitor of the crayfish neuromuscular junction by presynaptic voltage control. J Neurophysiol 77:103-115.

Wang LY, Kaczmarek LK (1998) High-frequency firing helps replenish the readily releasable pool of synaptic vesicles. Nature 394:384-388.

Xu J, He L, Wu LG (2007) Role of Ca(2+) channels in short-term synaptic plasticity. Curr Opin Neurobiol 17:352-359.

Zampini V, Johnson SL, Franz C, Lawrence ND, Münkner S, Engel J, Knipper M, Magistretti J, Masetto S, Marcotti W (2010) Elementary properties of $\mathrm{CaV} 1.3 \mathrm{Ca}(2+)$ channels expressed in mouse cochlear inner hair cells. J Physiol 588:187-199.

Zucker RS, Regehr WG (2002) Short-term synaptic plasticity. Annu Rev Physiol 64:355-405. 